\title{
Ensaios de padronização do teste ELISA para diagnóstico da cisticercose bovina utilizando antígenos de larva de Taenia crassiceps
}

\section{ELISA test standardization for the diagnosis of bovine cysticercosis employing Taenia crassiceps metacestode antigens}

\author{
Lilian Lameck Monteiro, ${ }^{*}$ Paulo Sérgio de Arruda Pinto, ${ }^{* *}$ Paula Dias Bevilacqua, ${ }^{* *}$ lacir Francisco dos Santos, ${ }^{* * *}$ Antônio \\ Augusto Mendes Maia, ${ }^{\star * * *}$ Francesca Silva Dias ${ }^{* * * *}$
}

\begin{abstract}
Resumo
Os antígenos total e vesicular de Taenia crassiceps e soros-controle de bovinos positivos e negativos para a cisticercose foram comparados por meio de alguns parâmetros de padronização do teste ELISA, visando avaliar o seu desempenho no diagnóstico da referida doença. Os parâmetros avaliados foram: diferentes concentrações dos antígenos, diluições de soros e conjugados, marcas de placa e substâncias bloqueadoras das placas. As diluições 1:25 de soro e 1:2.500 de conjugado para o antígeno de líquido vesicular e 1:5.000 para o antígeno total, o leite desnatado e as maiores concentrações dos antígenos testadas (1, 2 e $4 \mu \mathrm{g}$ /orifício) foram os critérios de padronização que proporcionaram maior diferenciação entre soros positivos e negativos, conseqüentemente, melhor desempenho do teste ELISA.
\end{abstract}

Palavras-chave: cisticercose bovina, Taenia crassiceps, ELISA, antígeno.

\begin{abstract}
Using the cyst fluid and the total antigens of Taenia crassiceps and positive and negative bovine control sera, some standardization parameters of one ELISA were compared, in order to evaluate its performance in the diagnosis of the bovine cysticercosis. The referred parameters were different antigen concentrations, dilutions of sera and conjugated, plate marks and blocking substances. The 1:25 dilution sera and 1:2.500 dilution conjugated for the cyst fluid antigen and 1:5.000 for the total antigen, the skimmed milk and the largest antigens concentrations (1,2 and $4 \mu \mathrm{g} /$ well) improved the differentiation among positive and negative sera, consequently, they were the best criteria for the bovine cysticercosis determination employing the ELISA.
\end{abstract}

Keywords: bovine cysticercosis, Taenia crassiceps, ELISA, antigen.

\section{Introdução}

A cisticercose bovina é uma zoonose, tendo o ser humano como único hospedeiro definitivo; já a sua forma larvar (Cysticercus bovis) tem como principais hospedeiros os bovinos e os búfalos (Ungar et al., 2001).

O complexo teníase-cisticercose, causado pela forma adulta do parasita em questão (Taenia saginata), apresenta distribuição cosmopolita, sendo encontrado principalmente nos países onde a pecuária bovina apresenta destaque (Souza et al., 1997).

No âmbito econômico, a importância dessa doença está relacionada com o número considerável de condenações das carcaças bovinas parasitadas. Neste aspecto, cumpre destacar que, nos últimos anos da década passada, a cisticercose constituiu a principal causa de condenação de bovinos em matadouros de Minas Gerais, registrando uma prevalência de 0,32-6,86\%, entre 1993 e 1997 (Queiroz et al., 2000).

Apesar da aplicação de vários métodos para controle da cisticercose bovina visando a quebra da cadeia da infecção, a inspeção de rotina continua sendo a principal medida de proteção da saúde pública pela interrupção da transmissão da T. saginata (Walther e Koske, 1980).

No entanto, a inspeção de carnes, por si só, não permite detectar todos os cisticercos presentes nas carnes, visto que, por razões de natureza comercial, o inspetor normalmente não retalha todos os órgãos, vísceras e carcaças submetidos

* Estudante de mestrado, Departamento de Veterinária, Universidade Federal de Viçosa, MG

** Professor(a) associado (a), Departamento de Veterinária, Universidade Federal de Viçosa, MG, Autor para correspondência: Departamento de Veterinária-UFV, CEP 36.570-000, Viçosa, MG, pintopsa@ufv.br

*** Professor titular, Faculdade de Veterinária, Universidade Federal Fluminense, Niterói, RJ

**** Professor adjunto, Faculdade de Zootecnia e Engenharia de Alimentos, Universidade de São Paulo, SP

*****Bolsista de Iniciação Científica, Departamento de Veterinária, Universidade Federal de Viçosa, MG 
à inspeção de rotina (Rodrigues, 1993). Ressalta-se ainda que a cisticercose bovina se apresenta, na maioria dos casos, sob a forma de infecção leve, o que, aliado à impossibilidade de se realizar um grande número de incisões nas carcaças e órgãos, aumenta a possibilidade de que muitos casos não sejam diagnosticados (Fukuda et al., 1998).

Assim, as limitações apresentadas pelo exame visual na detecção da cisticercose reforçam a necessidade da implementação de métodos diagnósticos alternativos mais confiáveis e eficientes para a detecção de animais infectados, independentemente da localização da lesão no organismo do animal (Walther e Koske, 1980; Ogunrinade e Oyekole, 1990).

O ELISA vem sendo pesquisado para aplicação no imunodiagnóstico da cisticercose, pois possui vantagens como versatilidade, bem como a possibilidade de ser adaptado à automatização dos equipamentos, permitindo assim seu emprego em diagnóstico de larga escala (Murrel et al., 1986).

Uma das dificuldades para obtenção de antígenos homólogos a serem usados em testes sorológicos deve-se ao fato de que os bovinos com infecção natural são mantidos na clandestinidade, sendo de difícil manipulação experimental, o que dificulta a escolha de antígenos adequados e em quantidade suficiente para garantir a homogeneidade e o controle de qualidade dos lotes antigênicos (Vaz, 1994). Outro fator que dificulta a obtenção de antígenos homólogos de larva de $T$. saginata em quantidade é o baixo grau de infecção dos animais parasitados (Geerts et al., 1981a).

Percebe-se, então, a necessidade de se desenvolver um modelo animal, de fácil manutenção em laboratório, como fonte alternativa de obtenção de parasitas para o preparo de antígenos heterólogos adequados a serem usados em testes diagnósticos.

A Taenia crassiceps é um cestódeo comum em raposas européias, e sua forma larvária (Cysticercus longicollis), encontrada em pequenos roedores (Freeman, 1962), tem sido pesquisada como fonte de antígenos heterólogos para o diagnóstico da cisticercose bovina, por propiciar, em certas ocasiões, resultados comparáveis àqueles obtidos com 0 uso de antígenos homólogos (Geerts et al., 1981b). As vantagens do emprego de antígenos heterólogos no diagnóstico da cisticercose também são destacadas por Hayunga et al. (1991).

O presente trabalho teve como objetivo comparar alguns parâmetros de padronização do teste ELISA para o diagnóstico da cisticercose bovina, ajustando o teste para uma proposta de aplicação prática.

\section{Material e métodos}

\section{Amostras de soros}

Foram utilizados dois soros de bovinos infectados experimentalmente por via oral com cerca de 100.000 ovos de $T$. saginata por animal e seis soros de bovinos negativos para cisticercose, criados em isolamento experimental, sob alimentação controlada desde o nascimento.

\section{Obtenção e preparo de antígenos de larva de T. crassiceps}

Os parasitas foram mantidos por infecção experimental com inoculação intraperitoneal de cinco a dez parasitas, formas pequenas sem brotamentos visíveis, em camundongos fêmeas BALB/c de 8-12 semanas. Após 90 dias, os animais com aumento do volume abdominal foram sacrificados e os parasitas então retirados cuidadosamente da cavidade peritoneal. Cisticercos em fase de degeneração ou calcificação foram eliminados e os demais foram utilizados no preparo dos antígenos. Os antígenos foram preparados conforme a metodologia utilizada por Pinto et al. (2000), com algumas modificações. O antígeno total de larva de T. crassiceps foi preparado a partir das seguintes etapas: desidratação "overnight" dos cisticercos por liofilização; trituração dos cisticercos desidratados em gral; adição de solução salina $0,15 \mathrm{M}$ obtendo uma proporção final de 6,5 a $10 \%$ (pó); homogeneização em homogeneizador de tecido tipo Potter, em banho de gelo; centrifugação a $17.400 \mathrm{~g} / 30 \mathrm{~min} / 4^{\circ} \mathrm{C}$; separação do sobrenadante para uso como antígeno; adição de inibidor de protease PMSF $(0,25 \mathrm{M}-10 \mu \mathrm{l} / \mathrm{ml})$; estocagem a $-20^{\circ} \mathrm{C}$. O antígeno de líquido vesicular de larva de T. crassiceps foi preparado a partir das etapas de centrifugação dos cisticercos a $35.000 \mathrm{~g} / 30 \mathrm{~min} / 4^{\circ} \mathrm{C}$; separação do sobrenadante para uso após a adição de inibidor de protease PMSF $(0,25 \mathrm{M}$ $-10 \mu \mathrm{l} / \mathrm{ml}$ ) e estocagem $\mathrm{a}-20^{\circ} \mathrm{C}$.

\section{Teste ELISA indireto}

A técnica empregada baseou-se nos testes realizados por Pinto et al. (2000).

\section{Padronização}

A padronização foi dividida em três fases, onde foram avaliados o tipo de substância bloqueadora, a marca de placa $^{1}$ e a titulação em bloco de antígeno, soro e conjugado, para definição das melhores concentrações ou diluições seriadas dos mesmos, considerando os dois tipos de antígenos. Cada fase se caracterizou pela avaliação simultânea de dois ou mais parâmetros, através da titulação em bloco. Os melhores parâmetros foram definidos por critério baseado na maior amplitude da diferença entre a média das densidades ópticas (DO) de dois soros-controle positivos e a média das DO de dois, quatro ou seis soros-controle negativos, em função do espaço disponível numa mesma placa.

No início dos testes de padronização, os períodos de incubação e a condição de bloqueio dos sítios reativos das placas foram fixados, convencionalmente, baseando-se na seleção prévia realizada por Pinto et al. (2000) para o diagnóstico da cisticercose suína.

Na fase 1, foram avaliados a melhor concentração do antígeno, as quatro melhores diluições de soro e a melhor marca de placa entre as duas testadas. As concentrações de antígeno testadas foram $0,25,0,5,1,2$ e $4 \mu \mathrm{g}$ por orifício da placa.

\footnotetext{
${ }^{1}$ Marca 1: Kartell ${ }^{\circledR}$, Byosystems Com. Imp. e Exp. de Equipamentos para laboratórios Ltda, Curitiba-PR.

Marca 2: Cral®, SL Suprimentos Laboratoriais Ltda, Belo Horizonte-MG.
} 
Foram empregados dois soros-controle positivos e dois soros-controle negativos em diluições seriadas (duas vezes), variando de 1:25 a 1:200. Nesta fase, o conjugado foi utilizado na diluição 1:5000.

$\mathrm{Na}$ fase 2, foi feita a avaliação do conjugado, partindo das melhores combinações de concentração de antígeno, marca de placa e diluições de soro verificadas na fase 1. Foram utilizados dois soros-controle positivos e quatro soros-controle negativos e as seguintes diluições seriadas (duas vezes) de conjugado: 1:625, 1:1.250, 1: 2.500, 1: 5.000, 1:10.000, $1: 20.000$ e $1: 40.000$.

Na fase 3, avaliou-se o tipo de substância bloqueadora: gelatina $1 \%$, albumina $1 \%$ e leite desnatado $5 \%$. Nesta fase 0 teste foi realizado com as melhores condições do antígeno, soros e conjugado, definidas nas fases anteriores.

\section{Análise dos resultados}

Os resultados foram processados e analisados através do programa de análises estatísticas, SAEG (1999). Procedeu-se à análise de variância das diferenças de DO entre dois soroscontrole positivos e dois, quatro ou seis soros-controle negativos obtidas em cada fase. Parâmetros que apresentaram diferença significativa $(p<0,05)$ foram testados através do teste Tukey, ao nível de $95 \%$ de probabilidade, visando determinar aquele que propiciava maior diferenciação entre soros-controle positivos e negativos. Valores que não apresentaram homogeneidade de variância foram submetidos à análise nãoparamétrica (teste Kruskal-Wallis) e teste de comparações múltiplas.

\section{Resultados e discussão}

$\mathrm{Na}$ primeira fase dos ensaios, realizada com o antígeno vesicular, verificou-se que a concentração de $1 \mu \mathrm{g} /$ orifício, na maioria das vezes, não foi estatisticamente diferente das concentrações maiores (2 e $4 \mu \mathrm{g} /$ orifício) sendo as três que mostraram melhor desempenho (Tabela 1). Embora a referida concentração tenha sido estatisticamente semelhante a concentrações menores em algumas diluições de soro, essa foi a escolhida para os testes seguintes (fases 2 e 3), visto que proporcionou elevados valores de médias entre soroscontrole positivos e negativos.

Embora praticamente não tenha se diferenciado das diluições maiores, a diluição 1:25 se destacou das demais por ter proporcionado, na maioria das vezes, maiores valores de média da diferença entre soros-controle positivos e negativos.

Ao analisar os resultados das quatro diluições de soro em conjunto, observou-se que não houve diferença significativa entre as marcas de placas, tanto para o antígeno vesicular, quanto para o total.

$\mathrm{Na}$ segunda fase observou-se uma nítida superioridade das reações diferenciais entre soros positivos e negativos, quando se testaram as diluições de soro 1:25 e 1:50, em comparação às diluições maiores, repetindo a tendência da primeira fase (Tabela 2).

Considerando ainda os resultados das diluições de soro 1:25 e 1:50, observou-se que a diluição de conjugado 1:2500 foi a que apresentou melhor desempenho devido às maiores médias apresentadas.
Tabela 1: Média da diferença de densidades ópticas ao teste ELISA entre soros-controle positivos e negativos, em função de diferentes diluições dos soros e concentrações ( $\mu \mathrm{g} /$ orifício) do antígeno de líquido vesicular de larva de T. crassiceps

\begin{tabular}{c|c|c|c|c}
\hline \multirow{2}{*}{$\begin{array}{c}\text { Concentrações } \\
\text { do antígeno }\end{array}$} & \multicolumn{4}{|c}{ Diluições dos soros } \\
\cline { 2 - 5 } & $1: 25^{(1)}$ & $1: 50^{(1)}$ & $1: 100^{(1)}$ & $1: 200^{(2)}$ \\
\hline $0,25^{(3)}$ & $0,018^{\mathrm{a}}$ & $0,039^{\mathrm{a}}$ & $0,016^{\mathrm{a}}$ & $0,018^{\mathrm{a}}$ \\
$0,5^{(4)}$ & $0,095^{\mathrm{b}, \mathrm{A}}$ & $0,089^{\mathrm{a}, \mathrm{b}, \mathrm{A}, \mathrm{B}}$ & $0,080^{\mathrm{a}, \mathrm{b}, \mathrm{A}, \mathrm{B}, \mathrm{C}}$ & $0,048^{\mathrm{a}, \mathrm{b}, \mathrm{A}, \mathrm{B}, \mathrm{C}}$ \\
$1^{(3)}$ & $0,137^{\mathrm{b}, \mathrm{c}}$ & $0,096^{\mathrm{a}, \mathrm{b}}$ & $0,079^{\mathrm{a}, \mathrm{b}}$ & $0,099^{\mathrm{a}, \mathrm{b}}$ \\
$2^{(4)}$ & $0,147^{\mathrm{b}, \mathrm{c}, \mathrm{A}}$ & $0,155^{\mathrm{b}, \mathrm{A}}$ & $0,098^{\mathrm{a}, \mathrm{b}, \mathrm{A}, \mathrm{B}}$ & $0,066^{\mathrm{a}, \mathrm{b}, \mathrm{B}}$ \\
$4^{(4)}$ & $0,185^{\mathrm{c}, \mathrm{A}}$ & $0,148^{\mathrm{b}, \mathrm{A}}$ & $0,190^{\mathrm{c}, \mathrm{A}}$ & $0,202^{\mathrm{b}, \mathrm{A}}$ \\
\hline
\end{tabular}

(1) Médias seguidas de pelo menos uma mesma letra minúscula, na mesma coluna, não diferem estatisticamente entre si pelo teste Tukey $(p>0,05)$.

(2) Médias seguidas de pelo menos uma mesma letra minúscula, na mesma coluna, não diferem estatisticamente entre si pelo teste Kruskal-Wallis ( $p>0,05)$.

(3) A ausência de letras maiúsculas na análise da linha significa que não houve diferença significativa entre as diluições de soros pela análise de variância.

(4) Médias seguidas de pelo menos uma mesma letra maiúscula, na mesma linha, não diferem estatisticamente entre si pelo teste Tukey $(p>0,05)$.

Tabela 2: Média da diferença entre densidades ópticas de soros-controle positivos e negativos em função de diferentes diluições de conjugado e diluições de soros para o antígeno de líquido vesicular de larva de T. crassiceps

\begin{tabular}{c|c|c|c|c}
\hline \multirow{2}{*}{$\begin{array}{c}\text { Diluições de } \\
\text { conjugado }\end{array}$} & \multicolumn{4}{|c}{ Diluições de soros } \\
\cline { 2 - 5 } & $1: 25^{(1)}$ & $1: 50^{(1)}$ & $1: 100^{(1)}$ & $1: 200^{(1)}$ \\
\hline $1: 625$ & $0,041^{\mathrm{a}, \mathrm{b}}$ & $0,047^{\mathrm{a}}$ & 0,010 & $-0,061^{\mathrm{a}}$ \\
$1: 1.250$ & $0,087^{\mathrm{a}, \mathrm{c}}$ & $0,110^{\mathrm{a}, \mathrm{c}}$ & 0,069 & $0,060^{\mathrm{a}, \mathrm{b}}$ \\
$1: 2.500$ & $0,191^{\mathrm{c}}$ & $0,123^{\mathrm{a}}$ & 0,061 & $0,085^{\mathrm{b}}$ \\
$1: 5.000$ & $0,176^{\mathrm{c}}$ & $0,060^{\mathrm{a}, \mathrm{c}, \mathrm{d}}$ & 0,041 & $0,008^{\mathrm{a}, \mathrm{b}}$ \\
$1: 10.000$ & $0,085^{\mathrm{a}, \mathrm{c}}$ & $0,068^{\mathrm{a}, \mathrm{c}, \mathrm{d}}$ & 0,038 & $0,012^{\mathrm{a}, \mathrm{b}}$ \\
$1: 20.000$ & $0,047^{\mathrm{a}, \mathrm{b}}$ & $0,024^{\mathrm{b}, \mathrm{c}}$ & 0,017 & $0,013^{\mathrm{a}, \mathrm{b}}$ \\
$1: 40.000$ & $0,030^{\mathrm{a}, \mathrm{b}}$ & $0,010^{\mathrm{b}, \mathrm{d}}$ & 0,004 & $-0,001^{\mathrm{a}}$ \\
\hline
\end{tabular}

(1) Médias seguidas de pelo menos uma mesma letra, na mesma coluna, não diferem estatisticamente entre si pelo teste Kruskal-Wallis $(p>0,05)$.

Nota-se que o leite desnatado exerceu melhor bloqueio dos sítios reativos remanescentes da placa, enquanto a gelatina apresentou pior desempenho (Tabela 3).

Analisando o antígeno total de larva de $T$. crassiceps quanto à variação de sua concentração, da diluição dos soros e do conjugado, da marca de placa e do tipo de substância bloqueadora foram observados os resultados mostrados nas Tabelas 4, 5 e 6.

Em algumas ocasiões, as concentrações maiores, de $2 \mu \mathrm{g} /$ orifício e $4 \mu \mathrm{g}$ /orifício de antígeno total de larva de $T$. crassiceps 
Tabela 3: Média da diferença entre densidades ópticas de soros-controle positivos e negativos, em função de diferentes substâncias bloqueadoras e diluições de soros para o antígeno de líquido vesicular de larva de T. crassiceps

\begin{tabular}{c|c|c|c|c}
\hline \multirow{2}{*}{$\begin{array}{c}\text { Substâncias } \\
\text { bloqueadoras }\end{array}$} & \multicolumn{4}{|c}{ Diluições dos soros } \\
\cline { 2 - 5 } & $1: 25^{(1)}$ & $1: 50^{(1)}$ & $1: 100^{(2)}$ & $1: 200^{(2)}$ \\
\hline Leite desnatado & $0,102^{\mathrm{a}}$ & $0,048^{\mathrm{a}, \mathrm{b}}$ & 0,021 & 0,023 \\
Albumina & $0,096^{\mathrm{a}}$ & $0,069^{\mathrm{a}}$ & 0,014 & 0,011 \\
Gelatina & $0,010^{\mathrm{b}}$ & $0,014^{\mathrm{b}}$ & 0,001 & $-0,010$ \\
\hline
\end{tabular}

(1) Médias seguidas de pelo menos uma mesma letra, na mesma coluna, não diferem estatisticamente entre si pelo teste Kruskal-Wallis ( $p>0,05)$.

(2) A ausência de letras, na mesma coluna, significa que não houve diferença significativa entre as substâncias bloqueadoras na análise de variância.

Tabela 4: Média da diferença de densidades ópticas ao teste ELISA entre soros-controle positivos e negativos, em função de diferentes diluições dos soros e concentrações ( $\mu \mathrm{g} /$ orifício) do antígeno total de larva de T. crassiceps

\begin{tabular}{c|cccc}
\hline $\begin{array}{c}\text { Concentrações } \\
\text { de antígeno }\end{array}$ & \multicolumn{4}{|c}{ Diluições dos soros $^{(2)}$} \\
\cline { 2 - 5 } & $1: 25$ & $1: 50$ & $1: 100$ & $1: 200$ \\
\hline 0,25 & $0,151^{\mathrm{a}, \mathrm{A}}$ & $0,089^{\mathrm{a}, \mathrm{A}, \mathrm{B}}$ & $0,076^{\mathrm{a}, \mathrm{A}, \mathrm{B}}$ & $0,089^{\mathrm{a}, \mathrm{A}, \mathrm{B}}$ \\
0,5 & $0,195^{\mathrm{a}, \mathrm{b}, \mathrm{A}}$ & $0,202^{\mathrm{b}, \mathrm{A}}$ & $0,157^{\mathrm{b}, \mathrm{c}, \mathrm{A}, \mathrm{B}}$ & $0,154^{\mathrm{a}, \mathrm{b}, \mathrm{A}, \mathrm{B}}$ \\
1 & $0,277^{\mathrm{b}, \mathrm{c}, \mathrm{A}}$ & $0,225^{\mathrm{b}, \mathrm{c}, \mathrm{A}, \mathrm{B}}$ & $0,209^{\mathrm{b}, \mathrm{c}, \mathrm{A}, \mathrm{B}}$ & $0,161^{\mathrm{a}, \mathrm{b}, \mathrm{B}}$ \\
2 & $0,258^{\mathrm{b}, \mathrm{c}, \mathrm{A}}$ & $0,278^{\mathrm{c}, \mathrm{A}}$ & $0,233^{\mathrm{b}, \mathrm{d}, \mathrm{A}, \mathrm{B}}$ & $0,211^{\mathrm{a}, \mathrm{b}, \mathrm{A}, \mathrm{B}}$ \\
4 & $0,302^{\mathrm{c}, \mathrm{A}}$ & $0,289^{\mathrm{c}, \mathrm{A}, \mathrm{B}}$ & $0,287^{\mathrm{d}, \mathrm{A}, \mathrm{B}}$ & $0,253^{\mathrm{b}, \mathrm{A}, \mathrm{B}}$ \\
\hline
\end{tabular}

(1) Médias seguidas de pelo menos uma mesma letra minúscula, na mesma coluna, não diferem estatisticamente entre si pelo teste Tukey $(p>0,05)$.

(2) Médias seguidas de pelo menos uma mesma letra, na mesma coluna, não diferem estatisticamente entre si pelo teste Tukey $(p>0,05)$.

Tabela 5: Média da diferença entre densidades ópticas de soros-controle positivos e negativos, em função de diferentes diluições de conjugado e diluições de soros para o antígeno total de larva de T. crassiceps

\begin{tabular}{c|c|c|c|c}
\hline \multirow{2}{*}{$\begin{array}{c}\text { Diluições de } \\
\text { conjugado }\end{array}$} & \multicolumn{4}{|c}{ Diluições dos soros } \\
\cline { 2 - 5 } & $1: 25$ & $1: 50$ & $1: 100$ & $1: 200$ \\
\hline $1: 625$ & $0,033^{\mathrm{a}, \mathrm{d}}$ & $0,065^{\mathrm{a}}$ & $0,120^{\mathrm{a}, \mathrm{c}}$ & $0,116^{\mathrm{a}, \mathrm{c}, \mathrm{d}}$ \\
$1: 1.250$ & $0,085^{\mathrm{a}, \mathrm{c}}$ & $0,153^{\mathrm{a}, \mathrm{b}}$ & $0,239^{\mathrm{a}}$ & $0,156^{\mathrm{a}, \mathrm{c}}$ \\
$1: 2.500$ & $0,187^{\mathrm{b}, \mathrm{c}}$ & $0,222^{\mathrm{b}}$ & $0,245^{\mathrm{a}}$ & $0,199^{\mathrm{a}}$ \\
$1: 5.000$ & $0,247^{\mathrm{b}}$ & $0,216^{\mathrm{b}}$ & $0,119^{\mathrm{a}, \mathrm{d}}$ & $0,107^{\mathrm{a}, \mathrm{c}, \mathrm{d}}$ \\
$1: 10.000$ & $0,117^{\mathrm{b}, \mathrm{c}, \mathrm{d}}$ & $0,087^{\mathrm{a}, \mathrm{b}}$ & $0,062^{\mathrm{b}, \mathrm{c}, \mathrm{d}}$ & $0,040^{\mathrm{b}, \mathrm{c}}$ \\
$1: 20.000$ & $0,056^{\mathrm{a}, \mathrm{d}}$ & $0,043^{\mathrm{a}}$ & $0,035^{\mathrm{b}, \mathrm{c}, \mathrm{d}}$ & $0,021^{\mathrm{b}, \mathrm{d}}$ \\
$1: 40.000$ & $0,016^{\mathrm{a}, \mathrm{d}}$ & $0,013^{\mathrm{a}}$ & $0,007^{\mathrm{b}, \mathrm{d}}$ & $0,002^{\mathrm{b}}$ \\
\hline
\end{tabular}

(1) Médias seguidas de pelo menos uma mesma letra, na mesma coluna, não diferem estatisticamente entre si pelo teste Kruskal-Wallis $(p>0,05)$. propiciaram valores mais elevados de média de diferença de DO entre soros positivos e negativos (Tabela 4). No entanto, optou-se pela escolha da concentração de $1 \mu \mathrm{g} /$ orifício para utilização na avaliação de marcas de placa e nas fases seguintes, pois não houve diferença estatística entre essas três concentrações, que mostraram melhor desempenho, nesta fase e em ensaios preliminares; além de permitir uma economia de antígeno. Minozzo et al. (2004) também verificaram melhor desempenho do teste ELISA, quando a concentração do antígeno total foi aumentada, no caso até 3 $\mu \mathrm{g}$ /orifício.

As diluições 1:25 a 1:200 de soros foram semelhantes estatisticamente, embora a diluição 1:25 tenha mostrado, na maioria das vezes, o maior valor médio da diferença de DO entre soros-controle positivos e negativos, para o antígeno total.

Observou-se que as diluições de conjugado 1:1.250, 1.2.500 e 1:5.000 mostraram maior amplitude da diferença entre as médias de DO de soros positivos e negativos (5). No prosseguimento da padronização preferiu-se adotar a diluição 1:5.000, em função da redução do custo da técnica quanto ao consumo de conjugado, um dos reagentes mais caros. Apesar de ter sido estatisticamente semelhante à diluição 1:10.000, a diluição de 1:5.000 foi preferida por ter proporcionado maiores valores absolutos de média da diferença entre soroscontrole positivos e negativos.

$\mathrm{Na}$ avaliação do tipo de substância bloqueadora verificou-se um pior desempenho do ELISA quando se utilizou a gelatina, o que foi demonstrado por DO mais elevada dos soros negativos em relação aos positivos, o que resultou em valores negativos de média da diferença entre esses dois grupos de soros (Tabela 6). O leite desnatado foi novamente a substância bloqueadora com desempenho estatisticamente superior, na metade das diluições analisadas, em relação à albumina. $\mathrm{Na}$ outra metade das diluições, apesar de ter apresentado semelhança estatística com a albumina, o leite desnatado apresentou também maior valor de amplitude da diferença entre as médias de DO de soros positivos e negativos para a diluição 1:100.

Tabela 6: Média da diferença entre densidades ópticas de soros-controle positivos e negativos, em função de diferentes substâncias bloqueadoras e diluições de soros para o antígeno total de larva de T. crassiceps

\begin{tabular}{c|c|c|c|c}
\hline \multirow{2}{*}{$\begin{array}{c}\text { Substâncias } \\
\text { bloqueadoras }\end{array}$} & \multicolumn{4}{|c}{ Diluições dos soros } \\
\cline { 2 - 5 } & $1: 25^{(1)}$ & $1: 50^{(2)}$ & $1: 100^{(2)}$ & $1: 200^{(2)}$ \\
\hline Leite Desnatado & $0,242^{\mathrm{a}}$ & $0,213^{\mathrm{a}}$ & $0,114^{\mathrm{a}}$ & $0,007^{\mathrm{a}}$ \\
Albumina & $0,038^{\mathrm{b}}$ & $0,050^{\mathrm{b}}$ & $0,038^{\mathrm{a}}$ & $0,012^{\mathrm{a}}$ \\
Gelatina & $-0,090^{\mathrm{c}}$ & $-0,044^{\mathrm{c}}$ & $-0,067^{\mathrm{b}}$ & $-0,068^{\mathrm{b}}$ \\
\hline
\end{tabular}

(1) Médias seguidas de pelo menos uma mesma letra, na mesma coluna, não diferem estatisticamente entre si pelo teste Tukey $(p>0,05)$.

(2) Médias seguidas de pelo menos uma mesma letra, na mesma coluna, não diferem estatisticamente entre si pelo teste Kruskal-Wallis $(p>0,05)$.

Os resultados mostraram um desempenho variável do ELISA para o diagnóstico da cisticercose bovina, em função da variação das concentrações de ambos os antígenos utilizados 
na pesquisa e das diluições de soros e conjugados, além do tipo de substância bloqueadora, apontando a importância destes parâmetros na padronização do teste para a referida finalidade. Ainda sugere-se que sejam privilegiados nos ensaios de ELISA para o diagnóstico da cisticercose bovina, as diluições 1:25 de soro e 1:2.500 de conjugado para o antígeno de líquido vesicular e 1:5.000 para o antígeno total de larva de

\section{Referências}

FREEMAN, R.S. Studies on the biology of Taenia crassiceps. Canadian Journal of Zoology, v. 40, p. 969-990, 1962.

FUKUDA, R.T.; SANTOS, I.F.; ANDRADE, C.R. Estudo comparativo entre técnicas de inspeção do diafragma para o diagnóstico da cisticercose bovina. Higiene Alimentar, v. 12, n. 55, p. 51-62, 1998.

GEERTS, S.; KUMAR, V.; AERTS, N.; CEULEMANS, F. Comparative evaluation of immunoelectrophoresis, counterimmunoelectrophoresis and enzyme linked immunosorbent assay for the diagnosis of Taenia saginata cysticercosis. Veterinary Parasitology, v. 8, p. 299-307, 1981a.

GEERTS, S.; KUMAR, V.; CEULEMANS, F.; MORTELMANS, J. Serodiagnosis of Taenia saginata cysticercosis in experimentally and naturally infected cattle by enzyme linked immunosorbent assay. Research in Veterinary Science, v. 30, p. 288-293, 1981b.

HAYUNGA, E.G., SUMNER, M.P., RHOADS, B.A., MURRELL, D., ISENSTEIN, R.S. Development of a serologic assay for cysticercosis, using an antigen isolated from Taenia sp cyst fluid. American Journal of Veterinary Research, v. 52, p. 462-470, 1991.

MINOZZO, J.C.; THOMAZ-SOCCOL, V.; OLORTEGUI, C.C.; SOARES, V.E.; COSTA, A.J. Teste imunoenzimático (enzyme- linked immunosorbent assay) para diagnóstico da cisticercose bovina e estudo da cinética de produção de anticorpos contra- Cysticercus bovis. Ciência Rural, v. 34, n. 3, p. 857-864, 2004.

MURREL, K.D.; FAYER, R.; DUBEY, J.P. Parasitic Organisms. Advances in Meat Research, v. 2, p. 311-376, 1986.

OGUNRINADE, A.F.; OYEKOLE, O.D. Evaluation of the efficiency of beef inspection procedures for tuberculosis, fascioliasis and cysticercosis in a nigerian abattoir. Preventive Veterinary Medicine, v. 8, p. 71-75, 1990.
T. crassiceps e o leite desnatado como substância bloqueadora, pois foram os critérios de padronização que proporcionaram maior diferenciação entre soros positivos e negativos, conseqüentemente, melhor desempenho do teste ELISA. As maiores concentrações de antígeno testadas (1, 2 e 4 g/orifício) também foram responsáveis por melhor desempenho do teste, considerando ambos os antígenos estudados.

PINTO, P.S.A., VAZ, A.J., GERMANO, P.M.L., NAKAMURA, P.M. Performance of the ELISA test for swine cysticercosis using antigens of Taenia solium and Taenia crassiceps cysticerci. Veterinary Parasitology, v. 88, p. 127-130, 2000.

QUEIROZ, R.P.V., SANTOS, W.L.M., BARBOSA, H.V., SOUZA, R.M., SANTOS FILHO, A.M.P. A importância do diagnóstico da cisticercose bovina. Higiene Alimentar, v. 14, n. 77, p. 12-15, 2000.

RODRIGUES, L.V.C. Inspeção sanitária e critério de julgamento da cisticercose bovina calcificada. Infecção leve. Ciência Rural, v. 23, n. 3, p. 339-344, 1993.

SISTEMA de análise estatística e genética (SAEG). Viçosa, MG: Folha de Viçosa, 1999.

SOUZA, R.M.; ANTUNES, C.F.; GUATIMOSIM, C.B.; RIBEIRO, R.M.P.; OLIVEIRA, A.L.; SANTOS, W.L. M. A importância do Serviço de Inspeção Federal na Vigilância Sanitária de Alimentos - Cisticercose Bovina. Higiene Alimentar, v. 11, n. 48, p. 19-21, 1997.

UNGAR, M.L.; GERMANO, M.I.S.; GERMANO, P.M.L. Cisticercose Bovina. In: GERMANO, P.M.L.; GERMANO, M.I.S. Higiene e vigilância sanitária de alimentos. 2. ed. São Paulo: Livraria Varela, p. 335-343, 2001.

VAZ, A.J. Diagnóstico da teníase e da cisticercose humana. In: ENCONTRODOCONESULESEMINÁRIOLATINOAMERICANOSOBRE TENÍASE E CISTICERCOSE, 1. 1994, Curitiba. Anaiss.n., Curitiba:SESA/ UFPR/OPAS/MS-FNS, p. 110-116, 1994.

WALTHER, M.; KOSKE, J.K. Taenia saginata cysticercosis: a comparison of routine meat inspection and carcase dissection results in calves. Veterinary Record, v. 106, p. 401-402, 1980. 